\title{
A randomized comparative study of exteriorization of uterus versus in situ intra-peritoneal repair at cesarean delivery
}

\author{
Sapna Chauhan*, Syamala Devi P. K.
}

Department of Obstetrics and Gynecology, Kerala Institute of Medical Sciences, Trivandrum, Kerala, India

Received: 24 October 2017

Accepted: 17 November 2017

\section{*Correspondence:}

Dr. Sapna Chauhan,

E-mail: sapna.chauhan1812@gmail.com

Copyright: (C) the author(s), publisher and licensee Medip Academy. This is an open-access article distributed under the terms of the Creative Commons Attribution Non-Commercial License, which permits unrestricted non-commercial use, distribution, and reproduction in any medium, provided the original work is properly cited.

\begin{abstract}
Background: Various caesarean delivery techniques have been compared in the past to assess the associated shortterm and long-term advantages and disadvantages. Although uterine exteriorization at caesarean section is popular among obstetricians, safety of this technique remains a disputed matter. The aim of the present study was to compare the influence of uterine exteriorization or in situ repair on caesarean section morbidity.

Methods: In this prospective, randomized, controlled study, 200 pregnant women with indication for caesarean delivery were randomized as 100 patients each in the exteriorization group and in the in-situ group. Data on mean time taken for uterine incision closure, intra-operative blood loss and post-operative morbidities were collected and compared between the two groups for statistical analysis.

Results: A statistically significant trend towards lesser mean time taken for the uterine wound repair was observed in the exteriorization group. However significantly more number of patients had increased post-operative pain and need for additional analgesia in exteriorization group. There was no significant difference with respect to intra-operative blood loss and incidence of nausea and vomiting; incidence of post-operative endomyometritis, febrile morbidity, wound infection, time taken for return of bowel function and length of hospital stay among the two groups.

Conclusions: We concluded that uterine exteriorization and in situ repair have similar post-operative caesarean section morbidity outcomes. However, in situ repair of uterus was associated with lesser post-operative pain, and exteriorization of uterus was associated with lesser operating time.
\end{abstract}

Keywords: Caesarean delivery, Exteriorization of uterus, In situ repair

\section{INTRODUCTION}

Caesarean delivery is one of the most commonly performed major surgical procedures worldwide. ${ }^{1}$ It represents the most significant operative intervention in all of obstetrics.

Its development and application has saved the lives of countless mothers and infants. On the other hand, its inappropriate use can be a direct and avoidable cause of maternal mortality and morbidity. As medical science and especially obstetrics has evolved over the recent years, there has been a parallel and steady increase in the rate of cesarean births.

The analysis suggests a strong inverse association between cesarean section rates and maternal, infant and neonatal mortality in countries with high mortality levels. Rates of cesarean section are of concern in both developed and developing countries. The global rate of cesarean section is estimated to be as $15 \%$ and the average cesarean section rate in Asia is $15.9 \% .^{2}$ The overall rate of cesarean section in India increased from $21.8 \%$ in $1993-1994$ to $25.4 \%$ in $1998-1999 .^{3}$ 
Cesarean section probably represents the main topic of controversy and debate in modern obstetrics for these reasons. Over the past few decades, safety of anesthetic techniques, effective antibiotic prophylaxis, facilities of blood transfusion and improved surgical techniques have contributed vastly in making cesarean delivery both safe and popular. Still cesarean delivery is not without morbidity and, the most optimal technique to limit maternal morbidity is still subject to debate.

And hence, there has been a constant endeavour on part of the obstetric fraternity to make cesarean delivery as much free of morbidity as possible so that child birth is fraught with fewer concerns than it is now.

A considerable decrease in the associated morbidity can be achieved with improvement in surgery techniques. Many variations in the technique of cesarean section have been devised, with the purpose of making the operation easier and more efficient, reducing costs, decreasing the risk of adverse effects, shortening the operating time and shortening postoperative morbidity and duration of hospital stay.

While details of operative technique are not more important than the question of whether or not there is a valid indication for the operation, these proposed variations are also important, and must be evaluated by randomized comparisons.

The method of uterine repair following delivery can either be with the uterus lying within the abdomen (in situ repair) or, uterus can be lifted through the incision on to the draped abdominal wall and the fundus covered with a moistened laparotomy pack (exteriorization). The majority of obstetricians prefer in situ repair, but many others continue to exteriorize the uterus as they are convinced of the surgical merit of the technique.

Exteriorization of uterus is said to have certain advantages. For example, the relaxed, atonic uterus can be recognized quickly, and massage applied. There is better visualization making the repair faster, simpler and easier, especially if there have been extensions laterally. Adnexal exposure is superior, which makes the tubal sterilization easier. The main disadvantage is intraoperative discomfort to the patient, nausea and vomiting caused by traction during exteriorization, hemodynamic instability, damage to the fallopian tubes, infection, and rupture or reduced flow of the uteroovarian veins which may lead to thrombosis or embolism. ${ }^{4-8}$ The effect of exteriorization of uterus over haemostasis during cesarean is still a matter of controversy. ${ }^{9-10}$

We performed this randomized study to compare intraoperative and perioperative outcomes with uterine exteriorization versus in situ repair of uterine incision at cesarean delivery.

\section{METHODS}

It was a prospective, single-blind, randomized, controlled study done over a period of 12 months from June 2012 to May 2013 in the Department of Obstetrics and Gynecology of KIMS Hospital (Kerala Institute Medical Sciences), a tertiary care health centre in South Kerala. The scientific and ethics committee of the study Hospital approved the study protocol. 200 pregnant women undergoing cesarean delivery for various elective and emergency indications who agreed to participate in the study by signing an informed consent form were included in the study and randomly allocated as 100 in the exteriorization group (Group 1) and 100 in the in-situ group (Group 2).

Patients with previous 2 or more caesareans, multiple pregnancy, placenta previa, premature rupture of membranes, previous laparotomy and those with any focus of infection diagnosed preoperatively were excluded from the study. All operations were performed by four registrar doctors who were comfortable with both the methods of uterine repair. Technique of performing surgery was standardized in all the 200 patients till delivery of the placenta, following which in the exteriorization group uterus was brought out of the peritoneal cavity for repair, while intra-peritoneal repair was done in in situ group. Remaining steps of the closure were also standardized in all 200 patients. All operations were performed under regional spinal anaesthesia and oxytocin management were standardized. Surgical antibiotic prophylaxis was standardized.

Intra-operative findings were noted for presence of any extension of the uterine incision, incidental uterine artery, bowel or bladder injury, any broad ligament hematoma formation or presence of any ovarian cysts etc. Time taken specifically for the uterine repair was noted (and not the overall surgery duration as it may get affected by many other factors like presence of intra-abdominal adhesions, concurrent tubal ligation etc.) Any incidences of intraoperative nausea and vomiting were noted.

Postoperatively all patients received intravenous fluids (Ringer Lactate and 5\% Glucose) at the rate of 100 $\mathrm{ml} /$ hour for 24 hours. Oral clear fluids were started 6 hours postoperatively.

Pain assessment was done 6 hours postoperatively using 10-point Visual analogue scale (VAS). Scores between 0 and 5 were defined as no/mild pain; scores between 6 and 10 were defined as moderate to severe pain. $50 \mathrm{mg}$ Diclofenac suppositories per rectum every 8 hours were administered during the postoperative period for pain relief and if the patient requested for additional analgesic doses, it was recorded as need for additional analgesia. Abdominal auscultation using stethoscope was done every 4 hours to assess return of bowel function. To estimate blood loss, the perioperative fall in hemoglobin estimation was calculated from the difference in 
preoperative and 48 hours postoperative hemoglobin estimations. The diagnosis of postoperative febrile morbidity was made in the presence of temp of $38^{\circ} \mathrm{C}$ $\left(100.4^{\circ} \mathrm{F}\right)$ on two occasions twelve hours apart excluding first post-op day. The diagnosis of postoperative endomyometritis was based on the presence of fever starting at $38^{\circ} \mathrm{C}\left(100.4^{\circ} \mathrm{F}\right)$, in the absence of any other cause, on two occasions twelve hours apart excluding the first postoperative day. Uterine tenderness, purulent or malodorous lochia and leucocytosis represent adjuvant criteria. Wound was assessed at post-op day-4 for evidence of infection (hematoma, purulent discharge, and breakdown). Length of hospital stay was recorded. The time taken from start of cesarean delivery until discharge from the hospital was taken as length of hospital stay.

The primary outcomes measured were intraoperative blood loss as reflected by difference in preoperative and postoperative hemoglobin value, incidence of endomyometritis and incidence of febrile morbidity.

The secondary outcomes measured were uterine closure time, incidence of intraoperative nausea/vomiting, assessment of pain 6 hours post-surgery using VAS for pain score, additional analgesic doses required on postoperative day-1, time taken for return of bowel function, incidence of wound infection, and length of hospital stay.

\section{Statistical analysis}

The demographic data of included women was presented as descriptive statistics (using range, mean and standard deviation). Demographic data and primary and secondary outcomes of both groups were compared. Student $t$ test was used for comparison of numerical data; the data were presented as mean $\pm \mathrm{SD}$.

Chi-square test was used for comparison of categorical data; the data were presented as frequencies (number of cases) and percentages. A 95\% limit and 5\% level of significance were adopted. Therefore, a $\mathrm{P}$ value of less than 0.05 was considered significant. Statistical analysis was done using SPSS software version 17.

\section{Objectives}

\section{Primary objective}

To assess intra-operative advantages and disadvantages, and post-operative morbidity following exteriorization of the uterus versus in situ repair of the uterine incision at cesarean delivery.

\section{Secondary objective}

To determine any surgical benefits and problems associated with the practice of routine exteriorization of the uterus to facilitate repair at cesarean delivery.

\section{RESULTS}

The study included 200 patients with an indication for cesarean delivery. The demographic profile and baseline clinical data like age, parity, pregnancy duration and indications for cesarean delivery were comparable in the two groups ( $\mathrm{P}$ value $>0.05)$ (Table 1$)$.

Table 1: Demographic and baseline characteristics of patients with cesarean delivery.

\begin{tabular}{|c|c|c|c|}
\hline Parameters & $\begin{array}{l}\text { Group } 1 \\
\text { (n=100) } \\
\text { (extra- } \\
\text { abdominal } \\
\text { repair) }\end{array}$ & $\begin{array}{l}\text { Group } 2 \\
\text { (n=100) } \\
\text { (in-situ } \\
\text { repair) }\end{array}$ & $\begin{array}{l}P \\
\text { value }\end{array}$ \\
\hline Age & $27.42 \pm 3.71$ & $27 \pm 3.82$ & 0.781 \\
\hline \multicolumn{3}{|l|}{ Parity } & \multirow{3}{*}{0.101} \\
\hline Nulligravida & $56(56)$ & $42(42)$ & \\
\hline Multigravida & $44(44)$ & $58(58)$ & \\
\hline $\begin{array}{l}\text { Pregnancy } \\
\text { duration (weeks) }\end{array}$ & $38.25 \pm 1.75$ & $38.02 \pm 1.96$ & 0.812 \\
\hline \multicolumn{3}{|c|}{ Indications for cesarean delivery } & \multirow{5}{*}{0.241} \\
\hline $\begin{array}{l}\text { Previous cesarean } \\
\text { delivery }\end{array}$ & $46(46)$ & $51(51)$ & \\
\hline Fetal distress & $35(35)$ & $37(37)$ & \\
\hline Dystocia / CPD & $10(10)$ & $7(7)$ & \\
\hline Malpresentation & $9(9)$ & $5(5)$ & \\
\hline \multicolumn{3}{|c|}{ Type of cesarean delivery } & \multirow{3}{*}{0.685} \\
\hline Elective & $40(40)$ & $44(44)$ & \\
\hline Emergency & $60(60)$ & $56(56)$ & \\
\hline
\end{tabular}

Abbreviation: CPD - Cephalopelvic Disproportion; Values are given as mean $\pm \mathrm{SD}$ or number (percentage)

The mean time taken for uterine incision closure in the exteriorization group was 11.40 minutes, standard deviation $=2.63$ and 12.40 minutes in the in-situ group, standard deviation $=2.70$.

A significant trend towards more time taken for the closure of the uterine incision in the in-situ group was observed $(\mathrm{P}=0.05)$ (Table 2). There were no significant differences with respect to, incidence of intraoperative nausea/vomiting $(\mathrm{P}$ value $>0.05$ ) (Table 2$)$.

Table 2: Intraoperative variables of women with cesarean delivery.

\begin{tabular}{|llll|}
\hline Variable & $\begin{array}{l}\text { Group 1 } \\
\text { (n=100) } \\
\text { (extra- } \\
\text { abdominal } \\
\text { repair) }\end{array}$ & $\begin{array}{l}\text { Group 2 } \\
\text { (n=100) } \\
\text { (in-situ } \\
\text { repair) }\end{array}$ & $\begin{array}{l}P \\
\text { value }\end{array}$ \\
\hline $\begin{array}{l}\text { Uterine incision } \\
\text { closure time } \\
\text { (minutes) }\end{array}$ & $11.4 \pm 2.63$ & $12.4 \pm 2.70$ & 0.05 \\
\hline $\begin{array}{l}\text { Incidence of } \\
\text { nausea/vomiting }\end{array}$ & $14(14)$ & $10(10)$ & 0.538 \\
\hline
\end{tabular}


The frequency of moderate-to-severe postoperative pain was significantly higher in exteriorization group (35\%) as compared to in situ group $(23 \%)(\mathrm{P}$ value $=0.025)$ (Table 3 ); and a significantly higher number of patients required additional number of analgesic doses on postoperative day-1 in the exteriorization group (20\%) as compared to in situ group $(\mathrm{P}$ value $=0.034)($ Table 3$)$.

Table 3: Postoperative variables of women with cesarean delivery.

\begin{tabular}{|c|c|c|c|}
\hline Variables & $\begin{array}{l}\text { Group } 1 \\
\text { (n=100) } \\
\text { (extra- } \\
\text { abdominal } \\
\text { repair) }\end{array}$ & $\begin{array}{l}\text { Group } 2 \\
\text { (n=100) } \\
\text { (in-situ } \\
\text { repair) }\end{array}$ & $\begin{array}{l}P \\
\text { value }\end{array}$ \\
\hline $\begin{array}{l}\text { Preoperative } \\
\text { haemoglobin, } \\
\mathrm{g} / \mathrm{dL}\end{array}$ & $12.13 \pm 0.935$ & $11.13 \pm 0.827$ & 0.416 \\
\hline $\begin{array}{l}\text { Postoperative } \\
\text { haemoglobin, } \\
\mathrm{g} / \mathrm{dL}\end{array}$ & $11.76 \pm 0.818$ & $10.61 \pm 0.892$ & 0.550 \\
\hline $\begin{array}{l}\text { Drop in } \\
\text { haemoglobin } \\
\text { level, g/dL }\end{array}$ & $0.37 \pm 0.101$ & $0.52 \pm 0.182$ & 0.752 \\
\hline $\begin{array}{l}\text { Moderate to } \\
\text { severe pain }\end{array}$ & $35(35)$ & $23(23)$ & 0.025 \\
\hline $\begin{array}{l}\text { Additional } \\
\text { postoperative } \\
\text { analgesia }\end{array}$ & $20(20)$ & $10(10)$ & 0.034 \\
\hline \multicolumn{4}{|c|}{ Time taken for return of bowel sounds } \\
\hline $6-8$ hours & $92(92)$ & $96(96)$ & \multirow{2}{*}{0.40} \\
\hline$>8$ hours & $8(8)$ & $4(4)$ & \\
\hline $\begin{array}{l}\text { Hospital stay, } \\
\text { days }\end{array}$ & $5.04 \pm 0.283$ & $5.18 \pm 0.629$ & 0.154 \\
\hline $\begin{array}{l}\text { Surgical site } \\
\text { infection }\end{array}$ & $4(4)$ & $2(2)$ & 0.558 \\
\hline Endomyometritis & $2(2)$ & $3(3)$ & 0.864 \\
\hline $\begin{array}{l}\text { Febrile } \\
\text { morbidity }\end{array}$ & $6(6)$ & $10(10)$ & 0.461 \\
\hline
\end{tabular}

However, there were no significant differences between the two groups in terms of intraoperative blood loss as reflected by difference in preoperative and postoperative hemoglobin value, incidence of endomyometritis and incidence of febrile morbidity in the postoperative period, time taken for return of bowel function, incidence of wound infection and length of hospital stay ( $\mathrm{P}$ value $>0.05$ ) (Table 3).

\section{DISCUSSION}

In the present study we compared the intra-operative advantages and disadvantages and postoperative morbidity following uterine exteriorization versus in situ repair during cesarean delivery; and to determine any surgical benefits and problems associated with the practice of exteriorization of the uterus to facilitate repair at cesarean delivery. 200 patients undergoing cesarean delivery were divided into two groups with 100 patients in each. The demographic profile and baseline clinical data like age, parity, pregnancy duration and indications for cesarean delivery were comparable in the two groups.

The mean time taken for uterine incision closure in the group 1 was 11.40 minutes, standard deviation $=2.63$ and 12.40 minutes in the group 2, standard deviation=2.70. A significant trend towards more time taken for the closure of the uterine incision in the in-situ group was observed in the present study. This may be attributable to the better visualization and easier repair of uterine incision following exteriorization. Shiya et al and khayat E et al reported significantly less duration of surgery in the exteriorization group as compared to in situ group in their studies. ${ }^{11,12}$ Hershey and Quilligan reported similar duration of surgery in their groups of women who underwent either uterine exteriorization or in situ repair.4

In the present study, the incidence of moderate-to-severe postoperative pain was more in group 1 (35\%) as compared to group $2(23 \%)$ and higher number of patients needed additional analgesia in group $1(20 \%)$ than in group 2 (10\%). These differences were statistically significant. The increased level of pain in the women who had undergone exteriorization of uterus may be attributable to the increased stretch on the uterine ligaments and parietal peritoneum. Khayat $\mathrm{E}$ et al reported $33 \%$ and $23 \%$ patients with moderate-to-severe postoperative pain respectively in group 1 and 2 and $20 \%$ and $10 \%$ patients respectively in group 1 and 2 needed additional analgesia which was significant. ${ }^{12}$

A systematic review and meta-analysis by Zaphiratos V et al also mentioned improved postoperative pain outcomes with in situ repair as suggested by several studies. ${ }^{13}$

We found no significant difference regarding intraoperative blood loss as reflected by postoperative drop in hemoglobin value between the two groups $(0.37 \pm 0.101$ and $0.52 \pm 0.182$ respectively). In contrast, Zaphiratos $\mathrm{V}$ et al in their study reported that exteriorization may be associated with a smaller decrease in hemoglobin and less estimated blood loss. ${ }^{13}$ However, in a study conducted by Magann EF et al to determine if blood loss at the time of cesarean section is affected by method of placental removal (spontaneous versus extracted) or uterine position for repair (in situ versus exteriorized), it was concluded that the method of placental removal and not the position of the uterus at the time of its repair has a significant role in blood loss during cesarean birth. ${ }^{14}$

The incidence of intraoperative nausea and vomiting was $14 \%$ in group 1 and $10 \%$ in group 2, which was not significant. These findings were similar to those reported by Khayat E et al and Edi-Osagie et al. ${ }^{12,15}$

In the present study the incidence of febrile morbidity was $6 \%$ in group 1 and $10 \%$ in group 2 . There was no 
significant difference between the two groups. Similar results were reported by Edi-Osagie et al in their study (4\% and $3 \%$ in both groups). ${ }^{15}$

The incidence of endometritis was noted to be $2 \%$ and $3 \%$ in group 1 and 2 respectively. The meta-analysis by Zaphiratos $\mathrm{V}$ et al revealed results that tended to favour in situ repair, but the difference was not statistically significant. ${ }^{13}$ However Coutinho IC et al reported $1.7 \%$ and $2 \%$ incidence of endometritis in exteriorization and in situ group respectively which was not significant. ${ }^{16}$

With regards to time taken for return of bowel function in postoperative period, we found no significant difference between the two groups with return of bowel function within 6-8 hours in 92\% patients in group 1 and $96 \%$ patients in group 2 . In contrast, Khayat $\mathrm{E}$ et al strongly favoured in situ repair in this regard and reported mean time to bowel movement to be longer in exteriorization group than in in situ group $(17.0 \pm 2.7$ hours versus 14.0 \pm 1.9 hours; $\mathrm{P}<0.001) .{ }^{12}$ Zaphiratos $\mathrm{V}$ et al have reported early return of bowel function with in situ repair. $^{13}$

In the present study we did not find any significant difference in the incidence of postoperative surgical site infection, $4 \%$ and $2 \%$ in group 1 and 2 respectively. Similarly, Coutinho IC et al found this incidence to be $7 \%$ in exteriorization group and $8.7 \%$ in in situ group which was not significant. ${ }^{16}$

In the present study, duration of hospital stay was observed to be similar in both the groups. However, Das et al have reported longer stay in in situ group. ${ }^{17}$ Duration of hospital stay was found to be similar in both the groups by Edi-Osagie et al. ${ }^{15}$

Similar to our study, Coutinho IC et al found that there is no significant difference between extra-abdominal and intra-abdominal repair of the uterine incision at cesarean delivery, but the number of sutures is lower and surgical time is shorter with extra-abdominal repair. Although moderate and severe pain at 6 hours is less frequent with in situ uterine repair. ${ }^{16}$ The study done by Ezechi et al showed that with shorter operative time, less blood loss and similar morbidity profile exteriorization of uterus during cesarean section seems to be preferred except where it is not possible because of adhesions and surgeon's inexperience. ${ }^{18}$

\section{CONCLUSION}

In conclusion, the ideal technique of uterine repair at cesarean delivery is a debatable subject. Our results show that, with similar safety and morbidity profiles in both the groups, exteriorization of uterus at cesarean delivery seems to be a valid option. However, the surgeon's experience and preference should determine the choice of technique of uterine repair. There was no evidence to suggest that exteriorization of the uterus at caesarean section has a more harmful influence on maternal morbidity than in situ repair.

\section{ACKNOWLEDGMENTS}

Author wishes to acknowledge and express her wholehearted thankfulness to her guide, Dr. Syamala Devi PK for her immense help and support during her study. She has guided the author in providing a scientific meaning to this study.

\section{Funding: No funding sources}

Conflict of interest: None declared

Ethical approval: The study was approved by the Institutional Ethics Committee

\section{REFERENCES}

1. Stirrat GM. The place of cesarean section. Contemporary reviews in Obstetrics and Gynecology. 1998;10:177-84.

2. Betran, Ana P, Merialdi M, Lauer JA, Bing-Shun W, Thomas J, et al. Rates of cesarean section: analysis of global, regional and national estimates. Paediatr Perinatal Epidemiol. 2007;21(2):98-113.

3. Kambo I, Bedi N, Dhillon BS, Saxena NC. A critical appraisal of cesarean section rates at teaching hospitals in India. Int $\mathbf{J}$ Gynaecol Obstet. 2002;79(2):151-8.

4. Hershey DW, Quilligan EJ. Extraabdominal uterine exteriorization at cesarean section. Obstet Gynecol. 1978;52:189-92.

5. Epps SN, Robbins AJ, Marx GF. Complete recovery after near-fatal venous air embolism during cesarean section. Int J Obstet Anesth. 1998;7:131-3.

6. Lowenwirt IP, Chi DS, Handwerker SM. Nonfatal venous air embolism during cesarean section: a case report and review of the literature. Obstet Gynecol Surv. 1994;49:72-6.

7. Siddiqui M, Goldszmidt E, Fallah S, Kingdom J, Windrim R, Carvalho JC. Complications of exteriorized compared with in situ uterine repair at cesarean delivery under spinal anesthesia: a randomized controlled trial. Obstet Gynecol. 2007; 110:570-5

8. Nafisi S. Influence of uterine exteriorization versus in situ repair on post-cesarean maternal pain: a randomized trial. Int J Obstet Anesth. 2007;16:135-8.

9. Jacobs-Jokhan D, Hofmeyr G. Extra-abdominal versus intra-abdominal repair of the uterine incision at cesarean section. Cochrane Database Syst Rev. 2004;4:CD000085.

10. Walsh CA, Walsh SR. Extraabdominal versus intraabdominal uterine repair at cesarean delivery: a metaanalysis. Am J Obstet Gynecol. 2009;200:625.e1-8.

11. Shiya A, Akhtar S, Khan S. Comparison of intraoperative and postoperative complications of intraabdominal versus extraabdominal uterine repair 
at cesarean delivery. Pak Armed Forces Med J. 2015;65:191-4.

12. El-Khayat W, Elsharkawi M, Hassan A. A randomized controlled trial of uterine exteriorization versus in situ repair of the uterine incision during cesarean delivery. Int $\mathrm{J}$ Gynaecol Obstet. 2014;127(2):163-6

13. Zaphiratos V, George RB, Colin J, Boyd, Habib AS. Uterine exteriorization compared with in situ repair for cesarean delivery: a systematic review and metaanalysis. Canadian J Anaesthesia. 2015;62(11):120920.

14. Magann EF, Dodson MK, Harris RL, Floyd RC, Martin RW, Morrison JC. Does method of placental removal or site of uterine incision repair alter endometritis after cesarean delivery? Infect Dis. Obstet Gynecol. 1993;1:65-70.

15. Edi-Osagie EC, Hopkins RE, Ogbo V. Uterine exteriorization at cesarean section: influence on maternal morbidity. $\mathrm{Br} \mathrm{J}$ Obstet Gynaecol. 1998;105:1070-8.
16. Coutinho IC, Amorim RMM, Katz L, Bandeira Ferraz AA. Uterine exteriorization compared with in situ repair at cesarean delivery: a randomized controlled trial. Obstet Gynecol. 2008;111:639-47.

17. Das S, Das P, Mahli A, Biswas S. Comparative study of uterine repair during cesarean section: Intraabdominal versus exteriorization of uterus. ISOR-JDMS. 2015;14(1):5-8.

18. Ezechi OC, Kalu BK, Njokanma FO, Nwokoro CA, Okeke GC. Uterine incision closure at cesarean section: a randomized comparative study of intraperitoneal closure and closure after temporary exteriorization. West Afr J Med. 2005;24:41-3.

Cite this article as: Chauhan S, Devi SPK. A randomized comparative study of exteriorization of uterus versus in situ intra-peritoneal repair at cesarean delivery. Int J Reprod Contracept Obstet Gynecol 2018;7:281-6. 